\title{
Intermittent ethanol binge exposure impairs object recognition but spares contextual and tone fear memory in adolescent rats
}

\author{
Nicole Tatit von Schaaffhausen ${ }^{1}$, Fernanda Alves Oliveira ${ }^{1}$, Thiago Nogueira Carvalho², Michel \\ Gonçalves Oliveira $^{2}$, Maria Helena Richtzenhain ${ }^{1}$ and Jair Guilherme Santos-Junior ${ }^{1},{ }^{2}$ \\ 1 Faculdade de Ciências Médicas da Santa Casa de São Paulo, Brazil \\ 2 Universidade Federal de São Paulo, Brazil
}

\begin{abstract}
Adolescent brain development seems to be important for the maturation of brain structures and behavior. Intermittent binge ethanol drinking is common among adolescents, and this type of drinking can induce brain damage and cognitive deficits. In addition, emotional changes are frequently seen in alcoholics and rodents treated with ethanol. Considering the close relation between emotional arousal and cognitive responses, the present work investigates if intermittent ethanol binge exposure could differentially alter the performance of adolescent rats in aversive and non-aversive motivated tests. Male adolescent rats were submitted to ethanol treatment $(2.5$ or $5.0 \mathrm{~g} / \mathrm{Kg}$, o.a.) at 48-h intervals over postnatal day (PND) 30 to 60 . Control animals were exposed to a similar administration protocol with saline administration. At PND61-PND63 animals were submitted to one-trial object recognition or contextual and tone fear conditioning paradigms. Binge ethanol drinking (at both 2.5 and $5.0 \mathrm{~g} / \mathrm{Kg}$ ) did not change freezing response in the contextual and tone fear conditioning. However, all doses impaired recognition rates $24 \mathrm{~h}$ after training in object recognition test. In addition, despite a diminution of horizontal locomotion in the open field (only for the $5.0 \mathrm{~g} / \mathrm{Kg}$ dose), no difference was detected regarding time in immobility, time in grooming and number of rearing in this paradigm. The present results show that the cognitive impairment resulting from intermittent binge ethanol exposure has a negative correlation with learning-associated emotional arousal Keyword: ethanol, binge drinking, adolescent rats, learning and memory, emotional arousal.
\end{abstract}

Received 22 September 2008; received in revised form 18 December 2008; accepted 18 February 2009. Available online 29 June 2009

\section{Introduction}

Heavy ethanol consumption has been reported to result in significant alterations of brain structure, physiology, and function. In fact, ethanol promotes brain injury and neurodegeneration in corticolimbic areas and results in memory impairment in both humans (Hildebrandt, Brokate, Eling, \& Lanz, 2004; Kim, Ke, \& Adkins, 2004; Ratti et al., 1999; Tedstone \& Coyle, 2004) and rodents (Crews et al., 2004, 2006; Garcia-Moreno et

Nicole Tatit von Schaaffhausen, Fernanda Alves Oliveira and Maria Helena Richtzenhain, Departamento de Ciências Fisiológicas, Faculdade de Ciências Médicas da Santa Casa de São Paulo, Brazil. Thiago Nogueira Carvalho and Michel Gonçalves Oliveira, Departamento de Psiquiatria e Medicina Psicológica, Universidade Federal de São Paulo, Brazil. Jair Guilherme Santos-Junior, Departamento de Fisiologia, Universidade Federal de São Paulo, Brazil and Departamento de Ciências Fisiológicas, Faculdade de Ciências Médicas da Santa Casa de São Paulo, Brazil. Correspondence regarding this article should be directed to: Jair Guilherme SantosJunior, Departamento de Ciências Fisiológicas, Faculdade de Ciências Médicas da Santa Casa de São Paulo, Rua Cesário Mota Jr., 61 / 11 andar, São Paulo, Brazil, CEP 01221-020. Phone/Fax: (55 11) 33312008. E-mail: guilherme.santos@fcmscsp.edu.br al., 2002; Obernier, Bouldin, \& Crews, 2002; Obernier, White, Swartzwelder, \& Crews, 2002; Roberto, Nelson, Ur, \& Gruol, 2002; Santucci et al., 2004).

Clinical and experimental studies have shown that the adolescent brain is more vulnerable to the neurodegenerative effects of ethanol (Crews, Braun, Hoplight, Switzer, \& Knapp, 2000; Dahl, 2004; Spear, 2000; White \& Swartzwelder, 2004), as well as to the functional consequences resulting from this neurodegenerative process, including learning and memory impairment (Acheson, Stein, \& Swartzwelder, 1998; White \& Swartzwelder, 2005).

Intermittent ethanol binge is common in adolescence. Differently from heavy ethanol drinking, relatively little is known about the functional consequences of this ethanol consumption pattern. Recently, Pascual and colleagues (2007) showed that intermittent ethanol binge promotes motor and cognitive impairment in adolescent rats as well as cell death in the neocortex, hippocampus, and cerebellum.

Besides learning and memory impairment, emotional changes have also been frequently reported in alcoholics (Grothues et al., 2008; Haynes et al., 2008) and in rodents submitted to ethanol consumption (Cabral et al., 2007; Läck, Diaz, Chappell, DuBois, \& McCool, 2007). In addition, 
emotional tone is clearly relevant in learning and memory processes (for a review see McGaugh, 2006; Roozendaal, Barsegyan, \& Lee, 2008). Curiously, the relation has not yet been described between the emotional arousal elicited by a task and the cognitively impairing effects of ethanol.

Thus, the aim of the present work was to assess whether intermittent ethanol binge exposure could differentially alter the performance of adolescent rats in aversive and non-aversive motivated tests. For this purpose we used object recognition test (a non-aversive motivated test) and fear conditioning (an aversive-motivated test). In the fear conditioning, an unconditioned aversive stimulus (foot-shock) was paired to a neutral conditioned stimulus (tone) in a specific context (equally neutral). After this association, the neutral stimuli acquired aversive properties and were thus able to promote fear responses in the animals (freezing). On the other hand, rodents naturally tend to approach and explore novel objects, even those objects which are assumed to have no natural meaning to the animal and which have never been paired with a reinforcing or aversive stimulus. Thus, differently from fear conditioning, the object recognition test is considered to be a poorly motivated task, involving low levels of arousal.

Considering the neurotoxicity of repeated ethanol withdrawal episodes, especially in the hippocampus, and the high anxiety levels during withdrawal, we hypothesized that intermittent ethanol binge exposures could impair the memory of animals in a non-aversive motivated test, while sparing the memory of animals in aversive motivated memory.

\section{Method}

\section{Subjects}

Thirty male Wistar EPM-1 rats [30 days old $($ PND30), initial weight $=150 \mathrm{~g}]$ were kept on a standard light/dark cycle (12/12h) with lights on at 07:00 AM, with free access to rat chow pellets and tap water. The animal care and experimental protocols were conducted under protocols approved by the Animal Care and Use Ethics Committee of the Faculty, according to the National Institute of Health Guide for the Care and Use of Laboratory Animals, 1996.

\section{Apparatus}

The open field and object recognition test was performed in a circular arena made of white wood (150 $\mathrm{cm}$ diameter), enclosed by stainless steel walls and divided in 19 squares by black lines. For the conditioning procedure in the fear conditioning, as well as in the contextual fear conditioning test, a passive avoidance apparatus from Ugo Basile (Italy) was used. Finally, for the tone fear conditioning, a cylindrical chamber of plexiglass (30 cm diameter x $60 \mathrm{~cm}$ height) was used.

\section{Binge ethanol protocol}

After a $4 \mathrm{~h}$ water and chow pellets deprivation, the animals received administrations of ethanol (Synth, Brazil) every other day, orally $[25 \%(\mathrm{v} / \mathrm{v})]$ at doses of 3 or $5 \mathrm{~g} / \mathrm{Kg}$ from PND 30 until PND60. Specifically, animals were treated at PND 30, 32, 34, 36, 38, 40, 42, $44,46,48,50,52,54,56,58$, and 60 . Thus, each animal was exposed on 16 occasions to alcohol, simulating the binge, an intermittent drinking pattern characteristic of young adolescents (Tur, Puig, Pons, \& Benito, 2003; White, Kraus, \& Swartzwelder, 2006). The saline control group received a similar treatment with saline. Thus, the following experimental groups were formed: Saline (animals submitted to saline treatment, from PND30 - PND60; $\mathrm{n}=8$ ), Et2.5 (animals submitted to ethanol treatment at the dose of $2.5 \mathrm{~g} / \mathrm{Kg}$, from PND30 - PND60; $\mathrm{n}=8$ ) and Et5 (animals submitted to ethanol treatment at the dose of $5.0 \mathrm{~g} / \mathrm{Kg}$, from PND30 - PND60; $\mathrm{n}=8$ ).

\section{Procedure}

The object recognition test and the contextual and tone fear conditioning were performed in the same animals, at PND61 - PND63. In the morning (08:00h - 12:00h) rats were submitted to the object recognition test, and in the afternoon $(14: 00 \mathrm{~h}-17: 00 \mathrm{~h})$ to the contextual and tone fear conditioning (see experimental design in Figure 1).

\section{Experiment 1 - Open field and object recognition test}

The object recognition test was performed according to Ennaceur and Delacour (1988), with some modifications. At PND61 all animals were given a single 10 -min habituation session with no objects in the open field arena. This habituation is crucial to improve the interaction of the animals with the objects during training and for the object recognition test. During the first five minutes we recorded the number of squares crossed, rearing, and time spent in immobility and in grooming (Archer, 1973). These parameters were used as an index of emotionality and to exclude possible bias resulting from locomotor impairment. Twenty four hours after habituation (PND62), training was conducted by placing

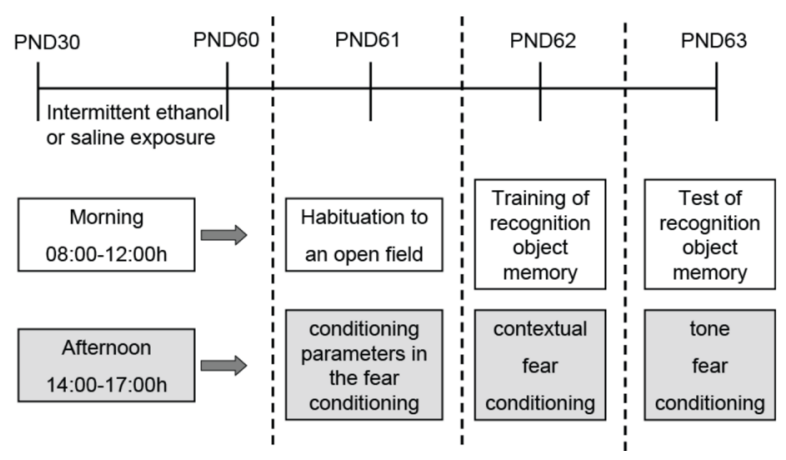

Figure 1. Illustration of experimental design. $\mathrm{PND}=$ postnatal day 
individual rats for 3 min into the field, in which two identical objects (A1 and A2; Lego toys) were positioned in two adjacent corners, $10 \mathrm{~cm}$ from the walls. After 24 $\mathrm{h}$ the test was conducted (PND63) when the same rats similarly explored the arena for $3 \mathrm{~min}$ in the presence of a familiar object A and a novel object B. A recognition index was calculated for each animal, and expressed by the ratio (time spent in interaction with object A1/time spent in interaction with objects $\mathrm{A} 1$ and $\mathrm{A} 2$, for training and time spent in interaction with object A1/time spent in interaction with objects $\mathrm{A}$ and $\mathrm{B}$, for $24 \mathrm{~h}$ retention). Both objects presented similar textures and sizes, but distinctive colors and shapes. In addition, between trials, the objects were washed with a $10 \%$ ethanol solution. Finally, exploration was defined as the time spent in sniffing or touching the object with the nose and/or forepaws. Sitting on the object was not considered exploration.

\section{Experiment 2-Contextual and tone fear conditioning}

\section{Conditioning parameters}

The conditioning procedure was performed at PND61. The rat was individually confined in the dark compartment of the passive avoidance apparatus. Two minutes later, the conditioned stimulus ( $5 \mathrm{~s}$ long) sounded, and in the last second a foot-shock of $1 \mathrm{~mA}$ and $1 \mathrm{~s}$ (unconditioned stimulus) was delivered, which finished together with the $70 \mathrm{~dB}$ tone (conditioned stimulus). The tone foot-shock pairing was repeated five times, $30 \mathrm{~s}$ apart. Thirty seconds after the last footshock, the animal was removed from the apparatus.

\section{Contextual fear conditioning}

The test was carried out at PND62. The animal was individually placed in the dark compartment of the apparatus, with the sliding door closed, where it remained for $5 \mathrm{~min}$. Unconditioned or conditioned stimuli were not delivered. The freezing time in each minute during the total 5 min was registered.

\section{Tone fear conditioning}

The test was carried at PND63. Each animal was individually placed in the cylindrical chamber (new context), where it remained for $8 \mathrm{~min}$. The chamber had been previously placed in another room to avoid spatial cues. The conditioned stimulus was presented 5 times at 30-s intervals, beginning at the end of the third minute. The freezing time was measured, minuteby-minute, during the first $3 \mathrm{~min}$ (before the tone) and during the final $5 \mathrm{~min}$ (during and after tone).

\section{Statistical analysis}

The data obtained in the contextual and tone fear conditioning were analyzed by one-way ANOVA for repeated measures followed by Newman-Keuls post hoc. The indexes of recognition in the training and $24 \mathrm{~h}$ retention, as well as the results from the open field test, were analyzed by one-way ANOVA followed by Newman-Keuls post hoc. Differences with $\mathrm{p}<.05$ were considered significant.

\section{Results}

\section{Experiment 1}

\section{Open field test}

The results of the open field test are depicted in Table I. The animals treated with ethanol at the dose of $5.0 \mathrm{~g} / \mathrm{Kg}$ crossed a smaller number of squares, when compared to both the Saline and Et2.5 groups $[\mathrm{F}(2,21)$ $=6.41 ; \mathrm{p}<.01$ and $\mathrm{p}<.05$, respectively]. However, no differences were seen between the experimental groups regarding time in immobility $[\mathrm{F}(2,21)=0.53 ; \mathrm{p}$ $=.59]$, time in grooming $[\mathrm{F}(2,21)=1.57 ; \mathrm{p}<.01]$, and rearing $[\mathrm{F}(2,21)=0.38 ; \mathrm{p}=.69]$.

Table 1. Effects of ethanol treatment over behaviour in the open field test.

\begin{tabular}{|c|c|c|c|c|}
\hline Groups & Squares crossed & Time in immobility (s) & Number of rearing & Time in grooming (s) \\
\hline Saline $(N=8)$ & $81.02 \pm 9.13$ & $112.75 \pm 11.79$ & $1.51 \pm 0.71$ & $37.02 \pm 10.57$ \\
\hline Et2.5 $(\mathrm{N}=8)$ & $58.21 \pm 5.36$ & $131.02 \pm 13.18$ & $1.91 \pm 0.77$ & $33.42 \pm 13.18$ \\
\hline $\operatorname{Et5}(\mathrm{N}=8)$ & $47.78 \pm 5.03 * * \#$ & $113.22 \pm 17.91$ & $1.11 \pm 0.42$ & $18.01 \pm 6.08$ \\
\hline
\end{tabular}

Data expressed as means \pm S.E.M. ${ }^{* *} \mathrm{P}<0.01$ in comparison to Saline group. $\# \mathrm{P}<0.05$ in comparison to Et2.5 group (ANOVA followed by Newman-Keuls). 


\section{Object recognition test}

Figure 2 shows the results of the object recognition test. No differences were seen between the experimental groups regarding the recognition index in the training session $[\mathrm{F}(2,21)=0.09 ; \mathrm{p}=.92]$. However, $24 \mathrm{~h}$ after training, a significant decrease in the recognition index was seen for both the Et2.5 and Et5 groups, when compared to the saline-treated group $[\mathrm{F}(2,21)=4.17 ; \mathrm{p}<.05]$.

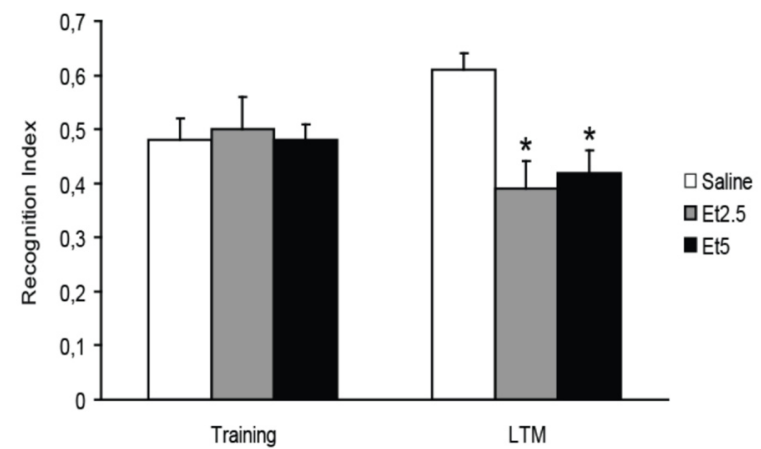

Figure 2. Recognition index performed by Saline ( $\mathrm{N}=8)$, Et2.5 $(\mathrm{N}=8)$ and $\mathrm{Et5}(\mathrm{N}=8)$ groups during training (PND62) and long-term memory - LTM (PND63). Recognition index was expressed as means \pm S.E.M. and calculated as a ratio [time of interaction with object $\mathrm{A} 1$ divided by the time of interaction with object $\mathrm{A} 1+\mathrm{A} 2$, for training], [time of interaction with above presented object (A) divided by the time of interaction with object $A$ and a new object (B), for LTM]. LTM=long-term memory. $* \mathrm{P}<0.05$ in comparison to Saline group.

\section{Experiment 2}

\section{Contextual fear conditioning}

The results obtained in the contextual fear conditioning are depicted in Figure 3. One-way ANOVA for repeated measures detected significant differences in the minute factor $[\mathrm{F}(2,21)=8.8 ; \mathrm{p}<.01]$, but not in the treatment factor $[\mathrm{F}(2,21)=0.37 ; \mathrm{p}=.69]$. In addition, no interaction was seen between factors $[\mathrm{F}(2,21)=1.22 ; \mathrm{p}=.29]$. Newman-Keuls post hoc revealed that all animals (despite of treatment) spent less time in freezing during the first minute of the test, when compared to the other minutes.

\section{Tone fear conditioning}

Figure 4 illustrates the data of the tone fear conditioning. One-way ANOVA for repeated measures detected significant differences in the minute factor $[\mathrm{F}(2,21)$ $=26.43 ; \mathrm{p}<.01]$, but not in the treatment factor $[\mathrm{F}(7,147)=$ $0.17 ; \mathrm{p}=.84]$. In addition, no interaction was seen between factors $[F(7,147)=1.58 ; p=.09]$. Newman-Keuls post hoc revealed that all animals (despite of treatment) showed greater freezing time in minutes 4,5 , and 6 (i.e. the period in which the conditioned stimulus was presented) when compared to minutes $1,2,3$ (i.e. the period prior to the conditioned stimulus presentation), 7 , and 8 (i.e. period after the conditioned stimulus presentation).

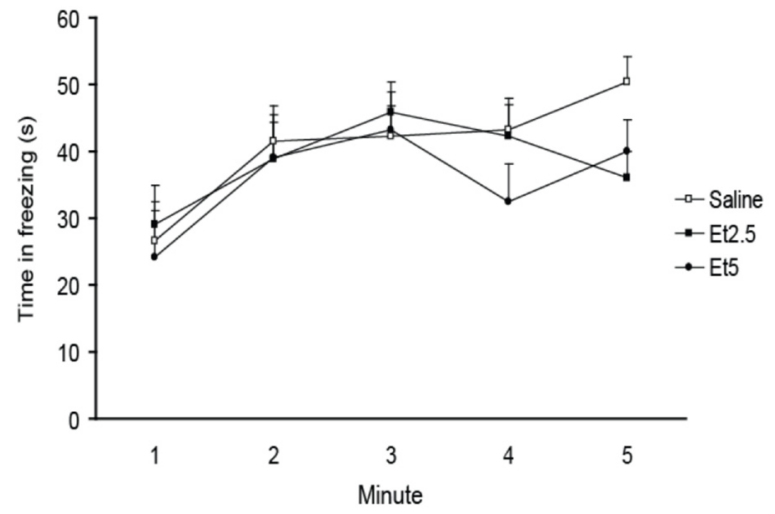

Figure 3. Performance of Saline $(\mathrm{N}=8), \mathrm{Et} 2.5(\mathrm{~N}=8)$ and $\mathrm{Et} 5(\mathrm{~N}=8)$ groups during $5 \mathrm{~min}$ of contextual fear conditioning. Each point represents the time in freezing. Data expressed as mean \pm S.E.M.

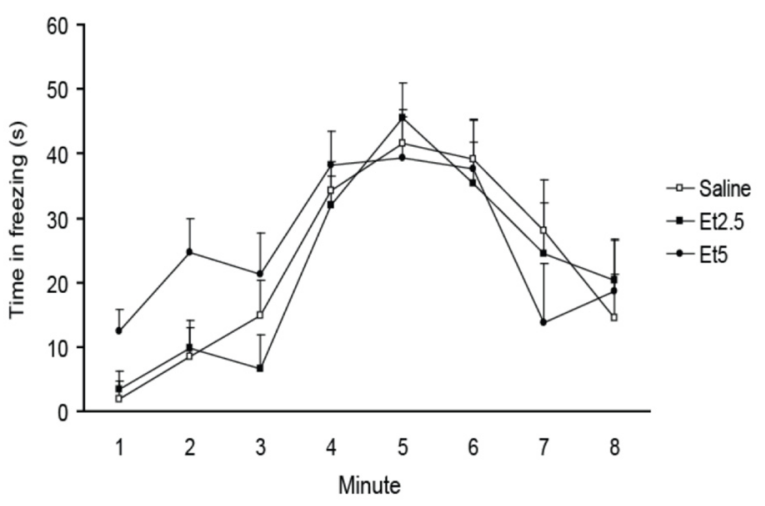

Figure 4. Performance of Saline $(\mathrm{N}=8)$, Et2.5 $(\mathrm{N}=8)$ and Et5 $(\mathrm{N}=8)$ groups in tone fear conditioning before, during and after tone presentation. The period from 1 to $3 \mathrm{~min}$ corresponds to freezing responses before tone presentation, and the period from 6 to $8 \mathrm{~min}$ corresponds to freezing responses after tone presentation. The tone was presented 5 times at 30-s intervals, beginning at the end of the $3 \mathrm{rd}$ minute. Data expressed as mean \pm S.E.M.

\section{Discussion}

The results of the present work show that intermittent ethanol binge exposure, impaired the memory for object recognition while sparing contextual and tone fear conditioning. Although a diminution of squares crossed was seen in the animals treated with ethanol at $5.0 \mathrm{~g} / \mathrm{Kg}$, the other parameters evaluated in the open field (rearing, time in immobility and in grooming) did not change. Thus, the differences encountered in the object recognition test are not related to a possible motor impairment induced by the ethanol. In addition, all behavioural tests were initiated $24 \mathrm{~h}$ after the last ethanol exposure, in a drugfree state. Obviously, emotional aspects could play an important role in the decrease in the number of squares crossed. In fact, high anxiety levels intensify the conflict between the drive to explore a new environment and the protection instinct, resulting in decreased exploratory activity (for a review see Lister, 1990 and Treit, 1985). It is important to mention that other variables, such as augment of grooming activity, are also related 
to anxiety. In addition, although in the Et5 group we observed a tendency to increased freezing response during the period before tone presentation in the tone fear conditioning (a good indicative of anxiety levels), this difference did not reach statistical significance $(\mathrm{p}=$ .18). Finally, the decrease in exploratory activity could be due to an anhedonic state in which the animals do not have sufficient motivation to explore a new environment. This hypothesis is in accordance with unpublished results from our laboratory that show a long-lasting increase of immobility in rats exposed to ethanol at a dose of $5.0 \mathrm{~g} / \mathrm{Kg}$ (but not $2.5 \mathrm{~g} / \mathrm{Kg}$ ). Thus, it is possible that the decrease in the number of squares crossed could be related to alterations of mood regulation.

Intermittent ethanol binge is common in adolescence. Differently from heavy ethanol drinking, relatively little is known about the functional consequences of this ethanol consumption pattern. Despite this, there is some evidence that memory problems develop after the cessation of prolonged alcohol intake rather than during drinking. In fact, Schandler, Clegg, Thomaz and Cohen (1996) found visuospatial learning to be more impaired in abstinent alcoholics than in those still intoxicated. In addition, memory deficits in rats were seen after withdrawal but not during alcohol intake (Farr, Scherrer, Banks, Flood, \& Morley, 2005; Lukoyanov, Madeira \& Paula Barbosa, 1999). Finally, alcoholics experiencing more withdrawal episodes had greater memory deficits (Duka, Townsend, Collier \& Stephens, 2003). Thus, it is possible that intermittent ethanol binge promotes greater memory deficits as compared to daily ethanol exposure.

In the fear conditioning, an unconditioned aversive stimulus (foot-shock) was paired to a neutral conditioned stimulus (tone) in a specific context (equally neutral). After this association, the neutral stimuli acquired aversive properties and were thus able to promote the fear response in the animals (freezing behaviour). Therefore, fear conditioning is a strongly aversive motivated test.

Considering contextual fear conditioning, some authors described that acute ethanol administration diminishes the freezing response (Gould \& Lommock, 2003; Land \& Spear, 2004; Lattal, 2007; Wehner et al., 2004), while Bertotto, Bustos, Molina and Martijena (2006) showed that the discontinuation from chronic ethanol administration facilitates the formation of a new contextual fear memory concomitant with a marked resistance to being extinguished (evidenced by intense freezing response). However, in the present work no difference was seen between the experimental groups regarding the freezing response in contextual fear conditioning. Our result corroborates the findings obtained by Borlikova, Elbers and Stephens (2006), in adult rats submitted to repeated withdrawal from ethanol.

In relation to tone fear conditioning, Bergstrom, McDonald and Smith (2006) showed that chronic ethanol consumption impaired tone fear conditioning after 30 days of withdrawal in adolescent rats. Similar features were seen in human binge drinkers (Stephens et al., 2005). In contrast, Land and Spear (2004) described no differences in the freezing response of adolescent rats treated with ethanol just prior to training. Despite the differences between patterns of ethanol exposure, our results corroborated the findings obtained in the latter work.

It is consensus that the amygdala plays a crucial role in the fear responses to tone and contextual aspects of conditioning (Gentile, Jarrel, Teich, McCabe, \& Schneiderman, 1986; Iwata, LeDoux, \& Reis, 1986; Phillips \& LeDoux, 1992). In addition, a review article showed that both lateral and central amygdaloid nuclei are essential in fear conditioning (Paré, Quirck, \& LeDoux, 2004). Nevertheless, hippocampal lesions impair only contextual fear conditioning (Kim \& Fanselow, 1992; Phillips \& LeDoux, 1992; Kjelstrup et al., 2002; Phillips \& LeDoux, 1992).

Rodents naturally tend to approach and explore novel objects, which are assumed to have no natural significance to the animal and which have never been paired with a reinforcing or aversive stimulus. Thus, different from fear conditioning, the object recognition test is considered to be a poorly motivated task, involving low levels of arousal. From this perspective, it is no surprise that evidence suggesting a role of the amygdala in object recognition is sparse (Roozendaal, Okuda, Van der Zee, \& McGaugh, 2006), while strong evidence describes the hippocampal formation as playing a crucial role in this process (Bermudez-Rattoni, Okuda, Roozendaal, \& McGaugh, 2005; Broadbent, Squire, \& Clark, 2004; Clark, Zola, \& Squire, 2000; de Lima, Luft, Roesler, \& Schröder, 2006; Ennaucer \& Aggleton, 1997; Winter \& Bussey, 2005a, 2005b). Despite this, even the role of the hippocampus in the object recognition test remains controversial (for a review see Dere, Huston and de Souza Silva, 2007).

Published evidence suggests that ethanol impairs the performance in the object recognition test. In fact, impaired recognition was seen both after acute (Brooks, Hennebry, McAlpin, Norman, \& Little, 2002) and chronic (Garcia-Moreno et al., 2002) ethanol administration. In addition, a recent article described that intermittent ethanol binge impaired object recognition in adolescent rats and promoted a significant increase in cell death in the neocortex, hippocampus and cerebellum (Pascual et al., 2007). Our results corroborate these previous findings, providing strong evidence that intermittent binge ethanol exposure disrupts object recognition memory. Considering that the hippocampal formation is necessary (although not sufficient) to normal behavioural responses in contextual fear conditioning and object recognition, it could be expected that intermittent ethanol binge exposure would result in similar impairments on both behavioural tests (but it did not). This discrepancy could be explained, at least in part, by the major role of 
the amygdala in the former but not in the latter test.

To summarize, the cognitive impairment resulting from intermittent ethanol binge had a negative correlation with learning-associated emotional arousal.

\section{Acknowledgements}

Research supported by FAP/FCMSCSP. J.G.S.J is a FAPESP fellow.

\section{References}

Acheson, S.K., Stein R.M., \& Swartzwelder, H.S. (1998). Impairment of semantic and figural memory by acute ethanol: age-dependent effects. Alcohol Clinical and Experimental Research, 22, 1437-1442.

Archer, J. (1973). Test for emotionality in rats and mice: a review. Animal Behavioral, 21, 205-235.

Bergstrom, H.C., McDonald, G.G., \& Smith, R.F. (2006). Alcohol exposure during adolescence impairs auditory fear conditioning in adult Long-Evans rats. Physiology \& Behavioral, 88, 446-472.

Bermudez-Rattoni, F., Okuda, S., Roozendaal, B., \& McGaugh, J.L. (2005). Insular cortex is involved in consolidation of object recognition memory. Learning and Memory, 12, 447-449.

Bertotto, M.E., Bustos, S.G., Molina, V.A., \& Martijena, I.D. (2006). Influence of ethanol withdrawal on fear memory: effect of D-cycloserine. Neuroscience, 142, 979-990.

Borlikova, G.G., Elbers, N.A., \& Stephens, D.N. (2006). Repeated withdrawal from ethanol spares contextual fear conditioning and spatial learning but impairs negative patterning and induces overresponding: evidence for effect on frontal cortical but not hippocampal function? European Journal of Neuroscience, 24, 205-216.

Broadbent, N.J., Squire, L.R., \& Clark, R.E. (2004). Spatial memory, recognition memory, and the hippocampus. Proceeding of the National Academy of Science of the United States of America, 101, 14515-14520.

Brooks, S.P., Hennebry, G., McAlpin, G.P., Norman, G., \& Little, H.J. (2002). Nimodipine prevents the effects of ethanol in tests of memory. Neuropharmacology, 42, 577-585.

Cabral, A., Isoardi, N., Salum, C., Macedo, C.E., Nobre, M.J., Molina, V.A., \& Brandão, M.L. (2006). Fear state induced by ethanol withdrawal may be due to the sensitization of the neural substrates of aversion in the dPAG. Experimental Neurology, 200, 200-208.

Clark, R.E., Zola, S.M., \& Squire, L.R. (2000). Impaired recognition memory in rats after damage to the hippocampus. Journal of Neuroscience, 20, 8853-8860.

Crews, F., Nixon, K., Kim, D., Joseph, J., Shukitt-Hale, B., Qin, L., et al. (2006). BHT blocks NF-KappaB activation and ethanol-induced brain damage. Alcohol Clinical and Experimental Research, 30, 1938-1949.

Crews, F.T., Braun, C.J., Hoplight, B., Switzer, R.C., \& Knapp, D.J. (2000). Binge ethanol consumption causes differential brain damage in young adolescent rats compared with adult rats. Alcohol Clinical and Experimental Research, 24, 1712-1723.

Crews, F.T., Collins, M.A., Dlugos, C., Littleton, J., Wilkins, L., Neasfsey, E.J., et al. (2004). Alcohol-induced neurodegeneration: when, where and why? Alcohol Clinical and Experimental Research, 28, 350-364.

Dahl, R.E. (2004). Adolescent brain development: a period of vulnerabilities and opportunities. Keynote address. Annals of the New York Academic Science, 1021, 1-22.

De Lima, M.N., Luft, T., Roesler, R., \& Schröder, N. (2006). Temporary inactivation reveals an essential role of the dorsal hippocampus in consolidation of object recognition memory. Neuroscience Letters, 405, 142-146.

Dere, E., Huston, J.P., \& De Souza Silva, M.A. (2007). The pharmacology, neuroanatomy and neurogenetics of one-trial object recognition in rodents. Neuroscience Biobehavioral Reviews, 31, 673-704.

Dos Santos, J.G.Jr., Longo, B.M., Blanco, M.M., Oliveira, M.G., \& Mello, L.E. (2005). Behavioral changes resulting from administration of cycloheximide in the pilocarpine model of epilepsy. Brain Research, 1066, 37-48.

Duka, T., Townsend, J.M., Collier, K., \& Stephens, D.N. (2003). Impairment in cognitive functions after multiple detoxifications in alcoholic inpatients. Alcoholism, Clinical and Experimental
Research, 27, 1563-1572.

Ennaceur, A., \& Delacour, J. (1988). A new one-trial test for neurobiological studies of memory in rats. 1: Behavioral data. Behavioral Brain Research, 31, 47-59.

Ennauceur, A., \& Aggleton, J.P. (1997). The effects of neurotoxic lesions of the perirhinal cortex combined to fornix transection on object recognition memory in the rat. Behavioral Brain Research, 88, 181-193.

Farr, S.A., Scherrer, J.F., Banks, W.A., Flood, J.F., \& Morley, J.E. (2005). Chronic ethanol consumption impairs learning and memory after cessation of ethanol. Alcoholism, Clinical and Experimental Research, 29, 971-982.

Garcia-Moreno, L.M., Conejo, N.M., Capilla, A., Garcia-Sanchez, O., Senderek, K., \& Arias, J.L. (2002). Chronic ethanol intake and object recognition in young and adult rats. Progress in Neuropsychopharmacolology and Biological Psychiatry, 26, 831-837.

Gentile, C.G., Jarrel, T.W., Teich, P.M., McCabe, P.M., \& Schneiderman, N. (1986). The role of amygdaloid central nucleus in the retention of differential Pavlovian conditioning of bradycardia in rabbits. Behavioral Brain Research, 20, 263-273.

Grothues, J.M., Bischof, G., Reinhardt, S., Meyer, C., John, U., \& Rumpf, H.J. (2008). Effectiveness of brief alcohol interventions for general practice patients with problematic drinking behavior and comorbid anxiety or depressive disorders. Drug and Alcohol Dependence, 94, 214-220.

Gould, T.J., \& Lommock, J.A. (2003). Nicotine enhances contextual fear conditioning and ameliorates ethanol-induced deficits in contextual fear conditioning. Behavioral Neuroscience, 117, 1276-1282.

Haynes, J.C., Farrell, M., Singleton, N., Meltzer, H., Araya, R., Lewis, G., et al. (2008). Alcohol consumption as a risk factor non-recovery from common mental disorder: results from the longitudinal followup of the National Psychiatry Morbidity Survey. Psychological Medicine, 38, 451-455.

Hildebrandt, H., Brokate, B., Eling, P., \& Lanz, M. (2004). Response shifting and inhibition, but not working memory, are impaired after longterm heavy alcohol consumption. Neuropsychology, 18, 203-211.

Iwata, J., LeDoux, J.E., \& Reis, D.J. (1986). Destruction of intrinsic neurons in the lateral hypothalamus disrupts cardiovascular but not behavioral conditioned emotional response. Brain Research, 368, 161-166.

Kim, J.J., \& Fanselow, M.S. (1992). Modality-specific retrograde amnesia of fear. Science, 256, 675-677.

Kim, K.Y., Ke, V., \& Adkins, L.M. (2004). Donepezil for alcoholrelated dementia: a case report. Pharmacotherapy, 24, 419-421.

Kjelstrup, K.G., Tuvnes, F.A., Steffenach H.A., Murison R., Moser, E.I., \& Moser, M.B. (2002). Reduced fear expression after lesions of the ventral hippocampus. Proceeding of the National Academy of Science of the United States of America, 99, 10825-10830.

Läck, A.K., Diaz, M.R., Chappell, A., DuBois, D.W., \& McCool, B.A. (2007). Chronic ethanol and withdrawal differentially modulate preand postsynaptic function at glutamatergic synapses in rat basolateral amygdala. Journal of Neurophysiology, 98, 3185-3196.

Land, C., \& Spear, N.E. (2004). Fear conditioning is impaired in adult rats by ethanol doses that do not affect periadolescents. International Journal of Developmental Neuroscience, 22, 355-362.

Lattal, K.M. (2007). Effects of ethanol on encoding, consolidation, and expression of extinction following contextual fear conditioning. Behavioral Neuroscience, 121, 1280-1292.

Lister, R.G. (1990). Ethologically-based animal models of anxiety disorders. Pharmacology \& Therapeutics, 46, 321-340.

Lukoyanov, N.V., Madeira, M.D., \& Paula Barbosa, M.M. (1999). Behavioral and neuroanatomical consequences of chronic ethanol intake and withdrawal. Physiology \& Behavior, 66, 337-346.

McGaugh, J.L. (2006). Make mild moments memorable: add a little arousal. Trends in Cognitive Science, 10, 345-347.

Obernier, J.A., Bouldin, T.W., \& Crews, F.T. (2002). Binge ethanol exposure in adult rats causes necrotic cell death. Alcohol Clinical and Experimental Research, 26, 547-557.

Obernier, J.A., White, A.M., Swartzwelder, H.S., \& Crews, F.T. (2002). Cognitive deficits and CNS damage after a 4-day binge ethanol exposure in rats. Pharmacology Biochemistry and Behavioral, 72, 521-532.

Paré, D., Quirck, G.J., \& LeDoux, J.E. (2004). New vistas on the amygdale network in conditioned fear. Journal of Neurophysiology, 92, 01-09.

Pascual, M., Blanco, A.M., Cauli, O., Miñarro, J., \& Guerri, C. (2007). Intermittent ethanol exposures induce inflammatory brain damage and causes long-term behavioural alterations in adolescent rats. European Journal of Neuroscience, 25, 541-550. 
Phillips, R.G., \& LeDoux, J.E. (1992). Differential contribution of amygdale and hippocampus to cued and contextual fear conditioning. Behavioral Neuroscience, 106, 274-285.

Ramos, A., \& Mormede, P. (1998). Stress and emotionality: a multidimensional and genetic approach. Neuroscience and Biobehavioral Review, 22, 33-57.

Ratti, M.T., Soragna, D., Sibilla, L., Giardini, A., Albergati, A., \& Savoldi, F. (1999). Cognitive impairment and cerebral atrophy in "heavy drinkers". Progress in Neuro-psychopharmacolology \& Biological Psychiatry, 23, 243-258.

Roberto, M., Nelson, T.E., Ur, C.L., \& Gruol, D.L. (2002). Longterm potentiation in the rat hippocampus is reversibly depressed by chronic intermittent ethanol exposure. Journal of Neurophysiology, 87, 2385-2397.

Roozendaal, B., Barsegyan, A., \& Lee, S. (2008). Adrenal stress hormones, amygdala activation, and memory for emotionally arousing. Progress in Brain Research, 167, 79-97.

Roozendaal, B., Okuda, S., Van der Zee, E.A., \& McGaugh, J.L. (2006). Glucocorticoid enhancement of memory requires arousalinduced noradrenergic activation in the basolateral amygdala. Proceeding of the National Academy of Science of the United States of America, 103, 6741-6746.

Santucci, A.C., Mercado, M., Bettica, A., Cortes, C., York, D., \& Moody, E. (2004). Residual behavioral and neuroanatomical effects of short-term chronic ethanol consumption in rats. Cognitive Brain Research, 20, 449-461.

Schandler, S.L., Clegg, A.D., Thomaz, C.S., \& Cohen, M.J. (1996). Visuospatial information processing in intoxicated, recently detoxified, and long-term abstinent alcoholics. Journal of Substance Abuse, 8, 321-333.

Spear, L. (2000). Modeling adolescent development and alcohol use in animals. Alcohol Research \& Health, 24, 115-123.
Stephens, D.N., Ripley, T.L., Borlikova, G., Schubert, M., Albrecht, D., Hogarth, L., \& Duka, T. (2005). Repeated ethanol exposure and withdrawal impairs human fear conditioning and depresses longterm potentiation in rat amygdala and hippocampus. Biological Psychiatry, 58, 392-400.

Tedstone, D., \& Coyle, K. (2004). Cognitive impairments in sober alcoholics: performance on selective and divided attention tasks. Drug and Alcohol Dependence, 75, 277-286.

Treit, D. (1985). Animal models for the study of anti-anxiety agents: a review. Neuroscience \& Biobehavioral Review, 9, 203-222.

Tur, J.A., Puig, M.S., Pons, A., \& Benito, E. (2003). Alcohol consumption among school adolescents in Palma de Mallorca. Alcohol, 38, 243-248.

Wehner, J.M., Keller, J.J., Keller, A.B., Picciotto, M.R., Paylor, R., Booker, T.K., et al. (2004). Role of neuronal nicotinic receptors in the effects of nicotine and ethanol on contextual fear conditioning. Neuroscience, 129, 11-24.

White, A.M., \& Swartzwelder, H.S. (2004). Hippocampal function during adolescence: a unique target of ethanol effects. Annals of the New York Academic Science, 1021, 206-220.

White, A.M., \& Swartzwelder, H.S. (2005). Age-related effects of alcohol on memory and memory-related brain function in adolescents and adults. Recent Developments in Alcoholism, 17, 161-176.

White, A.M., Kraus, C.L., \& Swartzwelder, H. (2006). Many college freshmen drink at levels far beyond the binge threshold. Alcoholism, Clinical and Experimental Research, 30, 1006-1010.

Winters, B.D, \& Bussey, T.J. (2005a). Glutamate receptors in perirhinal cortex mediated encoding, retrieval and consolidation of object recognition memory. Journal of Neuroscience, 25, 4243-4251.

Winters, B.D, \& Bussey, T.J. (2005b). Transient inactivation of perirhinal cortex disrupts encoding, retrieval and consolidation of object recognition memory. Journal of Neuroscience, 25, 52-61. 